\title{
The Influence of Tin Oxide Doping on Structural and Optical Properties of $\left(\mathrm{Bi}_{2} \mathrm{O}_{3}\right)$ Thin Films
}

\author{
Abdullah Mahmood Hussein Wlla Mohffod Mohammed Sabri Jassim Mohammed \\ College of Education for Pure Sciences, Department of Physics, University of Tikrit, Iraq \\ Aboodmoon900@gmail.com
}

\author{
ARTICLE INFO \\ Submission date: $19 / 7 / 2018$ \\ Acceptance date: $12 / 8 / 2018$ \\ Publication date: $14 / 10 / 2018$
}

\begin{abstract}
In this research, the powder mixing technology has been used to control the ratio of added, where the addition of tin oxide to the bismuth oxide of by $(1,3,5,7) \%$ by using vacuum evaporation method. The range of thickness for thin films (40-100)nm . EDX analysis shows the results of the ratios were close to the required values. XRD analysis shows pure bismuth oxide crystalline of the tetragonal phase $\left(\beta-\mathrm{Bi}_{2} \mathrm{O}_{3}\right)$, observed that the structural properties improves with addition (1)\% and the composition of a triangular compound $\left(\mathrm{Bi}_{64} \mathrm{SnO}_{98}\right)$, and with addition (5)\% we have a new triple compound $\left(\mathrm{Bi}_{12} \mathrm{SnO}_{20}\right)$. By increasing the impurities, the structural properties become close from random, the tin oxide begins with bismuth oxide separation. AFM measurement shows the thin films surface a pekes like (nano needle) and the grain size rises to $(20.2-22 \mathrm{~nm})$. In the case of increased impurities, the surface becomes smooth, and the nano needle decrease with grain size. The optical properties showed a rise in the value of the optical power gap (2.6-3)eV and directly allowed transitions are simply increasing from (3.3-3.5) $\mathrm{eV}$, and directly forbidden transitions are simply increasing to from $(2.48-2.73) \mathrm{eV}$.
\end{abstract}

Key words: .Bismuth oxide . Structure Properties $\left(\mathrm{Bi}_{2} \mathrm{O}_{3}\right)$. Optical properties $\left(\mathrm{Bi}_{2} \mathrm{O}_{3}\right)$

\section{Introduction}

Bismuth oxide $\mathrm{Bi}_{2} \mathrm{O}_{3}$ is one of the most important semiconductor substances that researchers are interested in studying [1] because of its optical and electrical properties such as large energy band gap, [2]. So far it is known that Bismuth has five main polymorphic forms $\alpha-\beta-\gamma-\delta$ and $\omega$ [3] Each of them has polymorph possesses different crystal structures and various energy band gap and mechanical properties [4]. $\alpha$-phase stabilizes in monoclinic at low temperature and high temperature $\delta$-phase centered cubic are stable, $\beta$-phase are tetragonal, $\gamma$-phase are body-centered and $\omega$-phase are triclinic in high temperature [5]. $\mathrm{Bi}_{2} \mathrm{O}_{3}$ is prepared with various techniques including vacuum evaporation, chemical analysis, chemical bath deposition and pulsed laser deposition [6]. The properties of $\mathrm{Bi}_{2} \mathrm{O}_{3}$ are altered by doping impurities to it that increase the ability to control optical and structural properties, as well as the improvement in electrical conductivity [7]. 


\section{Experimental}

\section{2-1- maxing}

In this research, tin and bismuth were used (Indian industry) in the form of high purity powder up to $99.9 \%$. Bismuth was used as base material (1-X) and tin as an additive and in weight $\mathrm{x}=(0.01,0.03,0.05,0.07)$ gram, Table(1) shows . After adding the tin to the bismuth, mix the mixture using a mortar of Agate for a period of (60 minutes). Then placed in mold of steel and press to $(5$ tons $/ \mathrm{cm} 2)$ for $(5$ minutes $)$ and then heated in the oven (German-made) to $100^{\circ} \mathrm{C}$. The size of the capsule is $(2.5 \times 10$ ) $\mathrm{mm}$.

Table(1) the weight of additions to prepare samples.

\begin{tabular}{|c|c|c|}
\hline Samples & Bi $(\mathrm{g})$ & Sn $(\mathrm{g})$ \\
\hline Pure & 1 & $\mathbf{1}$ \\
$1 \%$ & $\mathbf{0 9 9 2 1}$ & $\mathbf{0 . 0 1 3 3}$ \\
$3 \%$ & $\mathbf{0 9 7 4 3}$ & $\mathbf{0 . 0 3 8 4}$ \\
$\mathbf{5 \%}$ & $\mathbf{0 . 9 7 3 9}$ & $\mathbf{0 . 0 5 9 1}$ \\
$7 \%$ & $\mathbf{0 . 9 3 5 8}$ & $\mathbf{0 . 0 7 7 1}$ \\
\hline
\end{tabular}

\section{2-2- Method and Deposition}

The deposition was done using a vacuum evaporation system in vacuum (1.8 X $10^{-4} \mathrm{mpa}$ ) experimental technique to determine the thickness of the thin film. The experiment showed that the weight of the object inside a molpidium boat gives the thickness of a thin film, which is deposited on a glass base $(10.5) \mathrm{cm}$ height from the boat. The process evaporates relatively quickly so that the mixture cannot decompose because of the melting point difference. The molpidium boat was chosen as the mixture does not stick to it and when evaporated it floats on the boat but sticks to the tungsten boat. Thin films were heated under low pressure $1 \times 10^{-3}$ at $200^{\circ} \mathrm{C}$ for 60 minutes and left to cool before compressing pressure with atmospheric pressure. The thin film is oxidized in an oven with air temperature at $350^{\circ} \mathrm{C}$ for 60 minutes. The weighted method represented To calculate thickness, by equation (1)[8] .

$\mathrm{t}=\frac{\mathrm{m}_{2}-\mathrm{m}_{1}}{\mathrm{~A} \cdot \rho_{f}}$

Where $\mathrm{t}$ : thickness, $\mathrm{m}_{2}-\mathrm{m}_{1}$ : difference weight between $\mathrm{m}_{2}$ and $\mathrm{m}_{1}, \rho_{f}$ : Intensity of material, A: The area of the thin films.

\section{Results and discussion}

\section{3-1- Structural properties}

Figure (1) shows the results of the analysis structural properties of an different device type (SHIMADZU-Japan-XRD 6000). the thin film is composed of pure bismuth oxide $\left(\beta-\mathrm{Bi}_{2} \mathrm{O}_{3}\right)$, the results shows that the thin film has a crystalline structure of the tetragonal phase in which the directivity (201) is predominant at the angle (27.9) 
followed by the directivity (002) at the angle (31.7), followed by the directivity (220) and (402) in angles (32.7 and 57.7), these results were agreed with researchers $[4,9,10,11,16]$. The method of preparation produced a structure in the form of a nano needle up to (2.17) $\mathrm{nm}$ with grain size (20.2), topography by an AFM device (Nano PHYWE-German) show in Figure (2-A). The element analysis system (EDX) shows that the thin film composed of bismuth oxide, Bismuth weight of $(90 \%)$ and $(10 \%)$ relative to oxygen as shown in Fig (3-A). The results were agreed with international cards (American Standard For Testing Material) no: (027-0050) [16,11]. At the addition ratio $(\mathrm{x}=0.01)$ gram the thin film is composed $\left(\mathrm{Bi}_{2} \mathrm{O}_{3(\mathbf{0 . 9 9})} \mathrm{SnO}_{2(\mathbf{0 . 0 1})}\right)$. The results of the (x-Ray) analysis shows an improvement in the crystalline structure of the base compound with directivity remaining (201) at the angle (27.9) followed by directivity (211) at the angle (30.9) only, The analysis shows a triple compound $\left(\mathrm{Bi}_{64} \mathrm{SnO}_{98}\right)$ at directivity $(57.8)$ The results were agreed with (ASTM) cart no: (0420192). Figure (2-B) show Topography by an AFM device for, shows the structural nano needle with columns of up to (7.04)nm with grain size (20.4)nm. The (EDX) shows the ratio of $(\mathrm{Sn})$ is $1,63 \%$, which is slightly higher than the target ratio[11] . By increasing the value of $x$ to $(0.03)$ gram the structural properties of the then film shows a decrease in the intensity value of the X-ray deflected and change the angular direction of the $\left(\mathrm{Bi}_{64} \mathrm{SnO}_{98}\right)$ to angular (32.6) dy directivity (220) and $\left(\mathrm{Bi}_{2} \mathrm{O}_{3}\right)$ remained in the angular (27.9) dy directivity (201) , with up the value of surface compositions to (20.6) nm with grain size $(22 \mathrm{~nm})$ show in $\operatorname{Fig}(2-\mathrm{C})$.The (EDX) shows the ratio of $(\mathrm{Sn})$ is $3,23 \%$ the results were agreed with $[10,11,13-16]$ with differents method and materials. 
Journal of University of Babylon, Pure and Applied Sciences, Vol.(26), No.(9): 2018

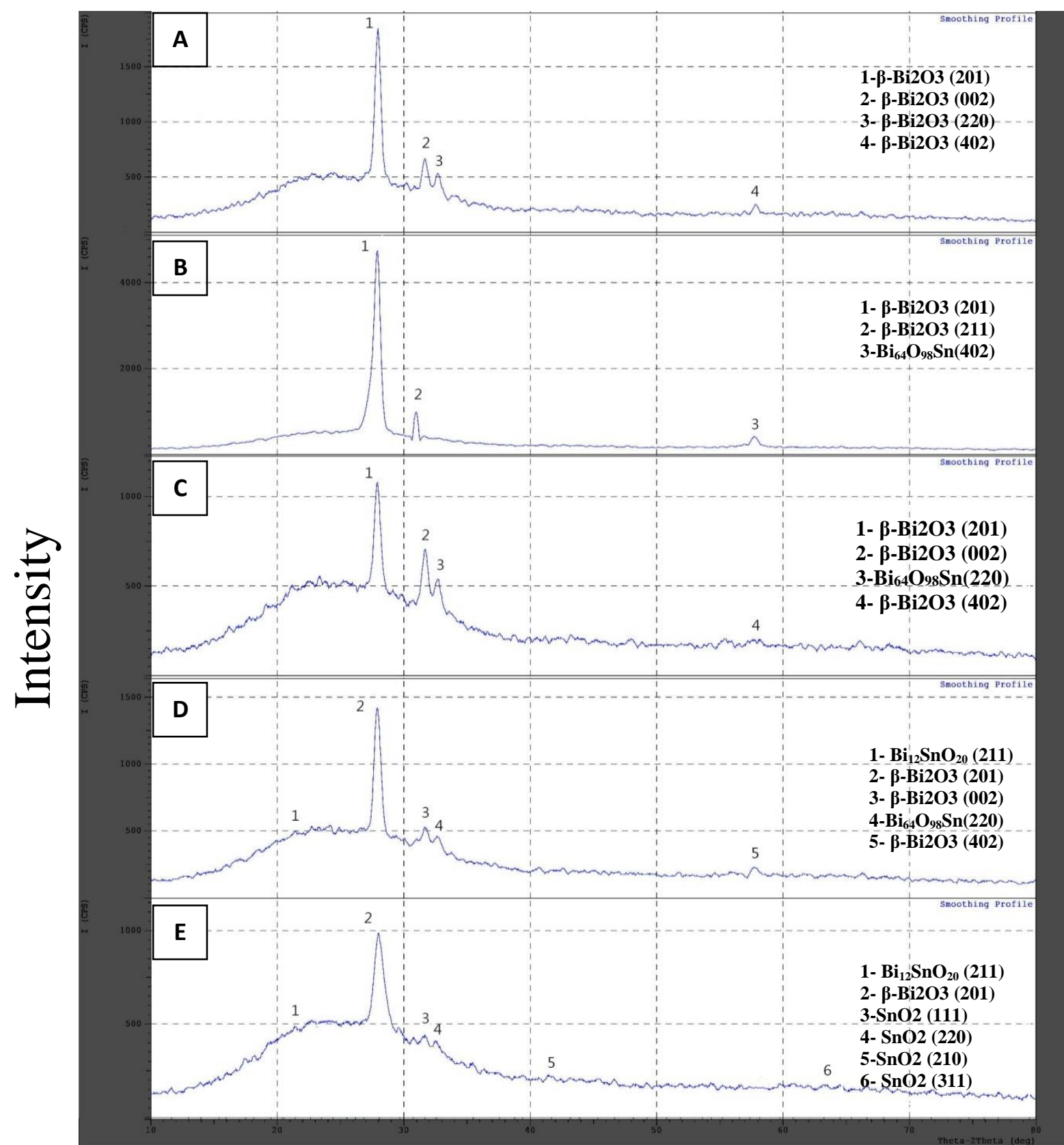

$2 \theta$

(Figure (1) XRD- A- Pure ; B- 1\% ; C- 3\% ; D- 5\% ; E - 7\%) 
Journal of University of Babylon, Pure and Applied Sciences, Vol.(26), No.(9): 2018
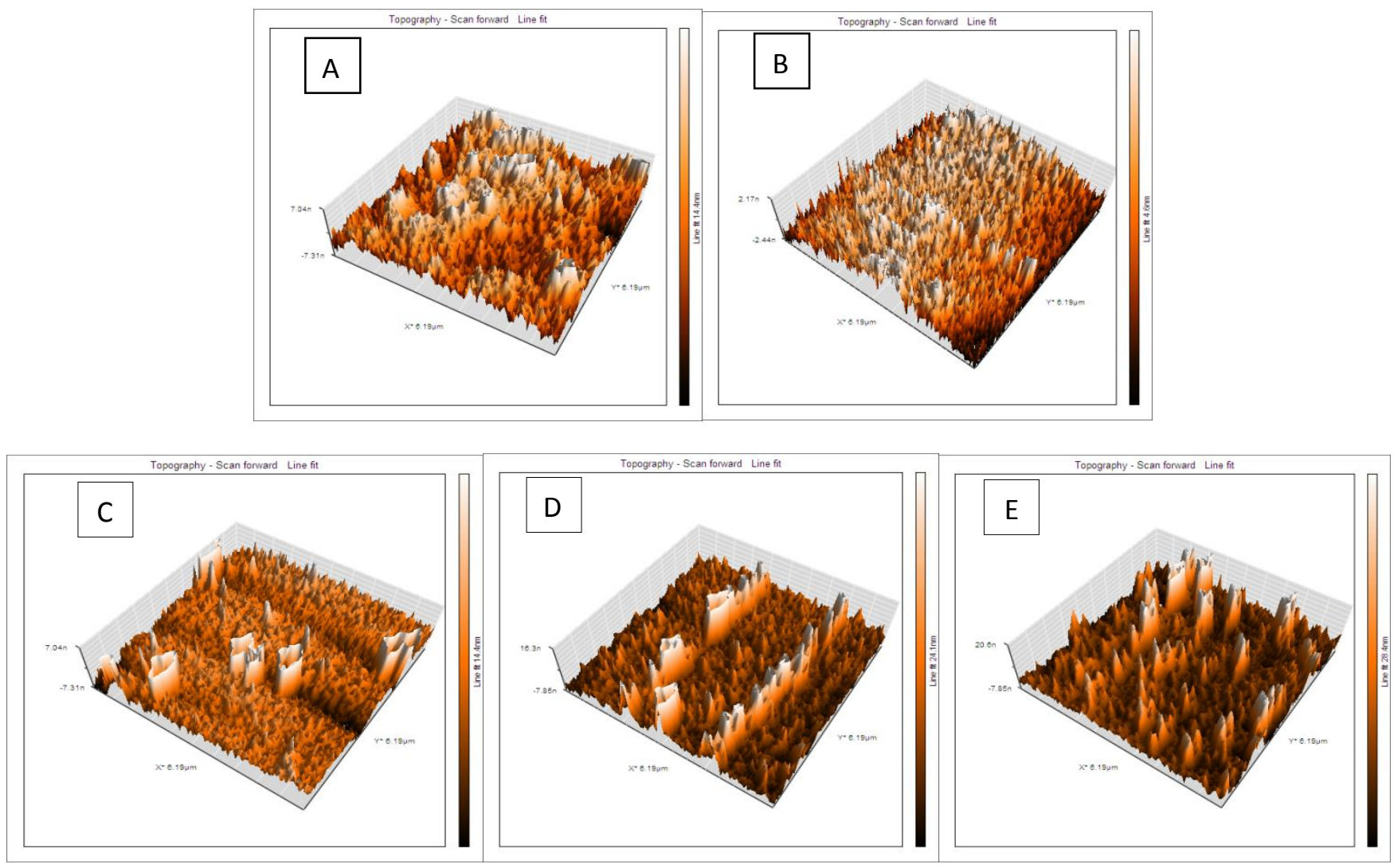

(Figure (2) AFM A-Pure ; B- 1\% ; C- 3\% ; D- 5\% ; E- 7\%) 

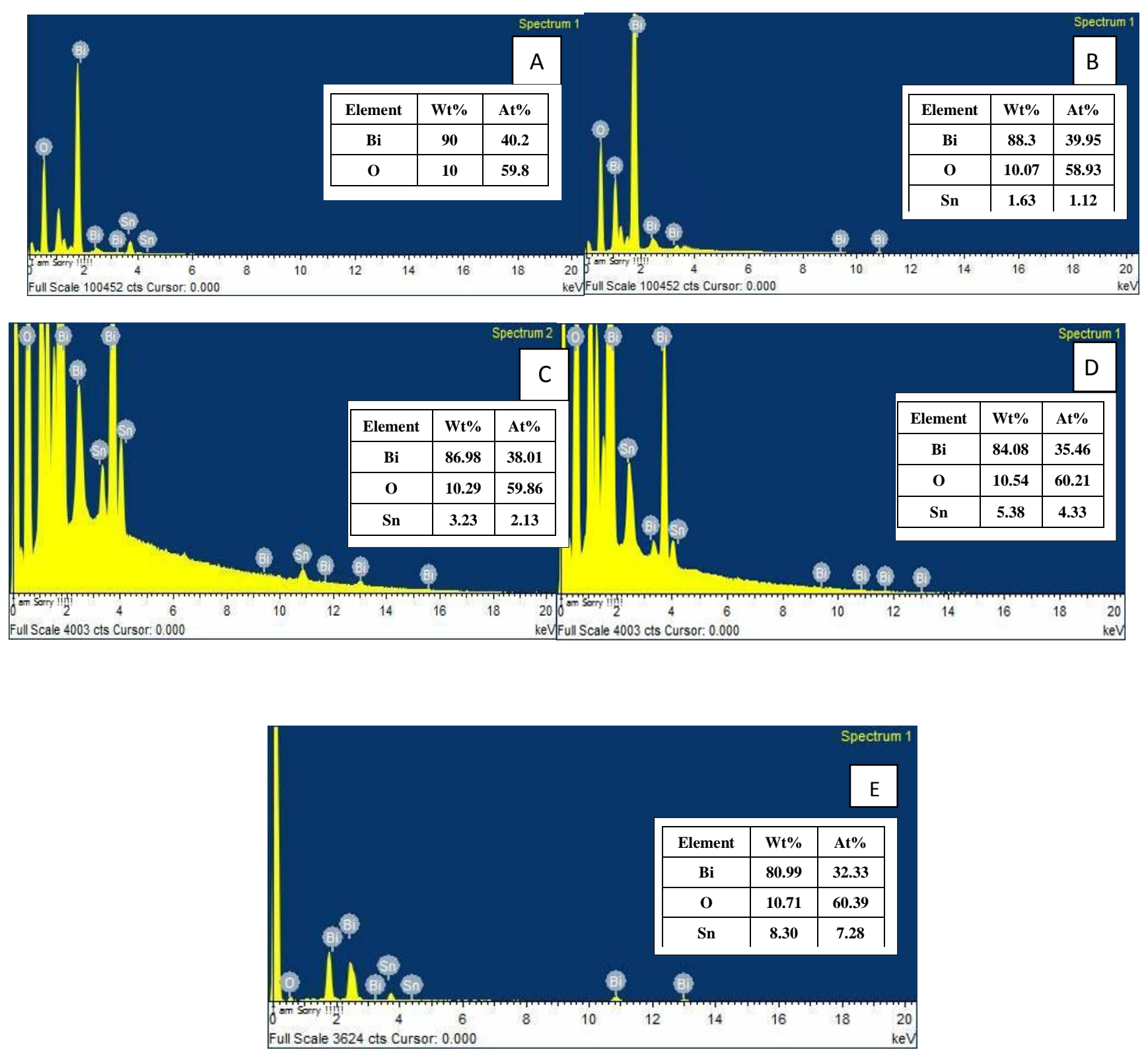

(Figure (3) EDX - A- Pure ; B- 1\% ; C- 3\% ; D- 5\% ; E- 7\%)

At the arrival of the addition ratio at $(\mathrm{X}=0.05)$ gram the triple compound (Bi64SnO98) can be observed in the same angle with a decrease in the value of the intensity as an indicator, but the analysis shows a new chemical triple compound (Bi12SnO20) according to the international card (ATSM) the numbered (054-1004) angle(21.4) by the directivity (211) and the percentage of add impurities in the card for the tin oxide is $(4.03) \%$. The topography of the surface is in Fig. (2-D), Shows a decrease in peaks to (7.5) with a decrease in the number of these peaks and a low grain size to (21.2)nm . The result of (EDX) analysis shows that the ratio of the tin oxide is equal to $(5.38) \%$, with an increase in the value of $X$ [10-13]. When increasing the addition to $(\mathrm{X}=0.07)$ gram ,the analysis shows a one peak of the bismuth oxide at the angle (27.9) with the triple compound $\left(\mathrm{Bi}_{12} \mathrm{SnO}_{20}\right)$ at angle (21.4) and the disappearance of compound $\left(\mathrm{Bi}_{64} \mathrm{SnO}_{98}\right)$, other peaks in these diffraction are for tin dioxide, this is due to the increase in the percentage of added impurities and that the 
tin oxide has been separated from the bismuth oxide and tapped on the surface. This addition has affected the crystalline structure leading to the random direction and decrease in the intensity of X-ray and particle size. The analysis of( EDX) shows that the ratio of the addition is (8.30), has increased, this confirms that there are loss ratios in the base substance Bismuth.

\section{3-2- Optical properties}

The optical properties of the thin films on glass bases were studied using ( Shimadzu1800-Japan spectrometer), where it measured permeability and absorption with a range of (300-900) $\mathrm{nm}$. Figure (4) shows the optical properties of pure bismuth where the absorption coefficient calculated using formula (2) [16]

$\alpha=2.303(\mathrm{~A} / \mathrm{t})$

Where, t:is thin film thickness, A :absorption . And energy gap calculated using formula(3) [16]

$(h v \alpha) y=\beta(h v-E g)$

Where hv is energy of photon $: \beta$ is a parameter : $y$ is index take the value(2) to calculate direct allowed transitions and(2/3) calculated direct forbidden transitions . The results showed that the optical energy gap (2.58)ev, direct allowed transitions (3.3)ev, and the direct forbidden transitions (2.48)ev. These results were agreed with researchers $[1,10,11,15,16]$ Figure (4) shows the optical properties of bismuth oxide thin film mixed with tin oxide. The results showed that the optical energy gap increases with increasing levels of tin oxide. Where it increased from (2.6ev to $3 \mathrm{ev}$ ), excluding the deviation by (3\%) where it decreased to $(2.3 \mathrm{ev})$, the results were similar to the researcher $[10,11]$, which was used for the doping using aluminum ,cerium. Where tin oxide at the ratio of (3\%) to the formation of new energy levels above the valance level. Increase the energy gap of the allowed direct transitions (3.3eV to $3.5 \mathrm{eV}$ ) and Increase the energy gap of the forbidden direct transitions (2.48ev to $2.73 \mathrm{ev}$ ). As a result of a reorganization in energy levels. 
Journal of University of Babylon, Pure and Applied Sciences, Vol.(26), No.(9): 2018
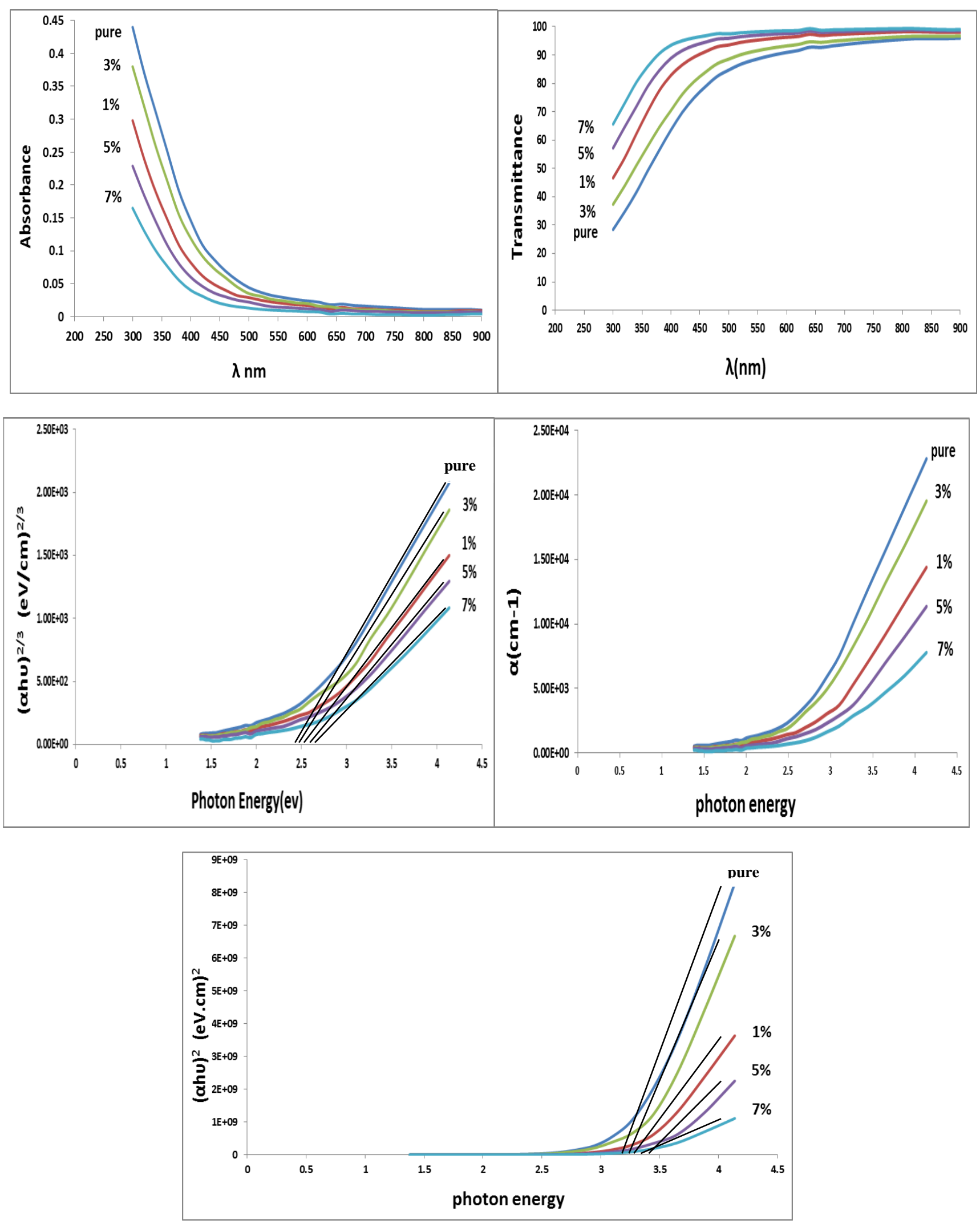

Figure (4)Results of UV-VIS 


\section{Conclusion}

Bismuth Oxide, Prepared by pressing and vacuum evaporation deposited on the glass substrate has $\beta$-phase. Structural properties showed an improvement by adding tin oxide $(1 \%)$ and obtaining the compound $\left(\mathrm{Bi}_{64} \mathrm{SnO}_{98}\right)$, in addition $(5 \%)$ we obtained a new compound $\left(\mathrm{Bi}_{12} \mathrm{SnO}_{20}\right)$, this proves that the material can be composed. The addition of the tin oxide by mixing and the pressure method using the weight ratios was close to the required ratios. Increasing the additive ratio nearing from random structural properties with the separation of tin oxide from bismuth oxide. The addition of tin oxide increases the optical energy gap.

\section{CONFLICT OF INTERESTS.}

There are non-conflicts of interest.

\section{References}

[1] Bushra. K. Hasson, Nassr. I. Najm "Effect of Thickness on the Structural and Optical Properties of (Bi2O3) thin films " Journal of College of Educatio ISSN: 18120380 Issue: 5 , PP: 75-88 (2016).

[2] H.T. Fan, S.S. Pan, X.M. Teng, C. Ye, G.H. Li, L.D. Zhang" $\delta$-Bi2O3 thin films prepared by reactive sputtering: Fabrication and characterization" Thin Solid Films . Volume 513, Issues 1-2, 14 , PP: 142-147, (2006).

[3] Reem Sami Ali "Structural and optical properties of nanostructure bismuth oxide" International Letters of Chemistry, Physics and Astronomy, ISSN 2299-3843, 15 PP:64-72 (2014)

[4] P. Gopinath1 , S. Sriram and R. Chandiramouli "Influence of Zn doping on nanostructured Bi2O3 thin films" International Journal of ChemTech Research. Vol.5, No.5, pp. 2534-2539, (2013)

[5] Hyoun Woo Kim, Jong Woo Lee and Chongmu Lee "Temperature-Controlled Fabrication of crystalline $\beta$ - Bi2O3 Nanowires through an MOCVD process" jounal of the Physical Society, Vol.50, No.5, pp.308-311, (2007).

[6] Raid A. Ismail, "Fabrication and Characteristics Study ofn-Bi2O3 /n-Si Heterojunction" Journal of Semiconductor Technology and Science, VOl.6, NO.2, (2006).

[7] Simona Condurache-Bota, Gheorghe I. Rusu, Nicolae ŢIGĂU, "Structural and Optical Characterization of Thermally Oxidized Bismuth Films" Revue Roumaine de Chimie, vol.54(3), pp. 205-211. (2009)

[8] Ali İmran Vaizoğullar, Ahmet Balc1, "Synthesis and Characterization of $\mathrm{ZnO} / \mathrm{SiO} 2$ Core-Shell Microparticles and Photolytic Studies in Methylene Blue' 'International Journal of Research in Chemistry and Environment, Vol.4, Issue 2, pp.161-165, (2014).

[9] Esra Özturk, Nilgun Ozpozan Kalaycioglu, Serkan Dayan and Handan Ozlu "Synthesis, characterization and oxide ionic conductivity of $\beta$-type solid solution in bismuth oxide doped with ytterbium oxide binary system" Bull. Mater. Sci, Vol. 36, No. 3, pp. 491-494. c Indian Academy of Sciences ,(2013)

[10] Bushra. K .Hasson, Nassr. I. Najm "The Influence of Aluminum Doping on Structural and Optical Properties of (Bi2O3)Thin Films" Ibn Al-Haitham Journal For Pure And Applied Science ISSN: 16094042, Volume: 29, Issue: 2 , pp. 387-396 ( 2016) 
[11] Xiao Guo-sheng, Liu Jia-lu , Liu Zhuo-jing , Zhang Feng-jun , Lyu Cong, "Preparation, Characterization and Visible-light-responsive Photocatalytic Activity of Cerium-doped Bismuth Oxide" Chinese Journal Of Luminescence, Vol. 35 No. 8, Issue: 8, pp.957-963, (2014).

[12] Rishabh Sharma, Manika Khanuja, Shailesh Narayan Sharma, Om Prakash Sinha "Reduced band gap \& charge recombination rate in Se doped a-Bi2O3 leads to enhanced photoelectrochemical and photocatalytic performance: Theoretical \& experimental insight",Volume 42, Issue 32, pp: 20638-20648, (2017).

[13] Shuangshuang Xue, Hongbo He, Qizhe Fan, Changlin Yu, Kai Yang, Weiya Huang, Yang Zhou, Yu Xie," La/Ce-codoped Bi2O3 composite photocatalysts with high photocatalytic performance in removal of high concentration dye, Journal of Environ Mental Sciences 60,PP:70-77, (2017).

[14] magnetron sputtering " Journal of Optoelectronics and advanced Materials Vol. 8, No. 3,PP: 1221 - 1224, (2006).

[15] L. Leontie, M. Caraman, M. Alexe, C. Harnagea, "Structural and optical characteristics of bismuth oxide thin films" Surface Science 507-510 , pp.480 485, (2002)

[16]Xin Yang, Xiaojuan Lian, Shangjun Liu, Gang Wang, Chunping Jiang, Jing Tian, Jinwei Chen and RuilinWang, "Enhanced photocatalytic performance: a $\beta$ Bi2O3 thin film by nanoporous surface"Journal of Physics D: Applied Physics, Vol .46 (2013).

\section{الخلاصة}

في هذا البحث , تم استخدام تقنية خلط المساحيق للتحكم في نسبة الإضافة حيث تمت إضافة أكسيد القصدير الى أوكسيد

البزموث بنسبة (1, 1 , 5 , 7) \% باستخدام طريقة التبخير بالفراغ , بمدى سمك للأغشية الرقيقة (100-40) نانومتر ـ اظهر تحليل

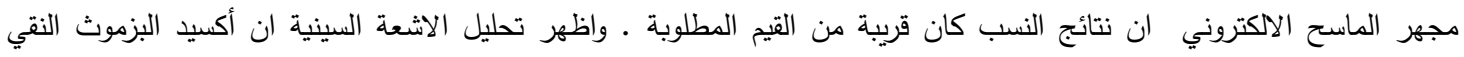

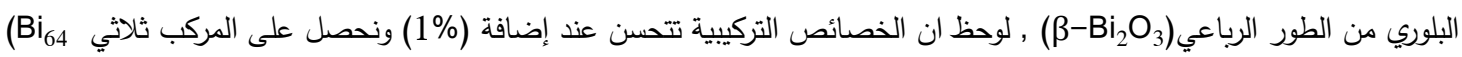

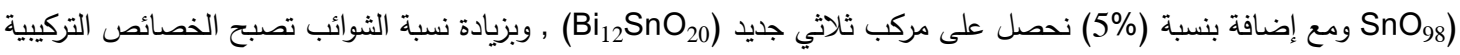

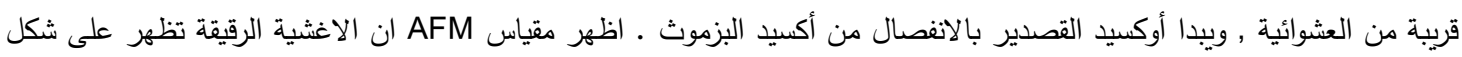

قمم تثبه الابر النانوية , وفي حالة زيادة الثوائب يصبح السطح ناعم , أظهرت الخواص البصرية ارتفاعا في قيمة فجوة الطاقة

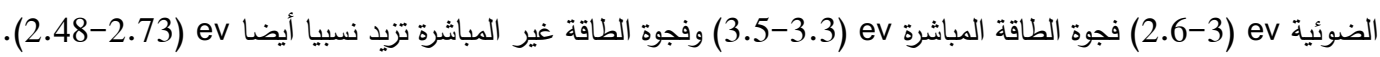
الكلمات الدالة: أوكسيد البزموث , الخواص التركيبية (3i 